\title{
An Unusual Microstructure for a Carbon Steel Tube
}

\author{
Mark A. Hineman, ${ }^{*}$ Michael J. Danko, ${ }^{*}$ Kent L. Johnson, ${ }^{*}$ and Frederick E. Schmidt, Jr.*
}

*Engineering Systems Inc., 3851 Exchange Avenue, Aurora, IL 60504

A 1010 steel elbow used in an automotive application had been formed from seam welded (ERW) tubing. Because a longitudinal mark was observed on the surface of the finished elbow, it was subjected to metallographic examination in order to determine if the surface mark was associated with the longitudinal seam weld. A metallographic cross section prepared through the mark revealed a shallow rounded groove approximately 0.001 " $(0.025 \mathrm{~mm})$ deep and 0.003 " $(0.075 \mathrm{~mm})$ wide when examined in the as-polished condition. In order to identify the position of the longitudinal seam weld, the polished cross section was etched with $2 \%$ nital.

Examination of the etched section revealed a curious microstructure. Dark etching layers were observed at the inside and outside circumference with a very light etching band below the dark layer at the outside circumference. The remainder of the thickness of the elbow displayed a mixture of light and dark etching grains. These grains were found to be comprised of ferrite (light) with martensite and/or bainite at the grain boundaries. Because the cold drawing operations result in work hardening of the product, several cycles of annealing may have been performed in order to soften the steel and ease deformation to the final wall thickness.

The annealing operations performed on this tubing often results in decarburization at the outside surface. Because of the length of the tubes, very little decarburization occurs on the inside surface. In addition, the cold working can promote grain growth of the decarburized layer during annealing. This would account for the light etching band below the outside circumference in the examined cross section.

The dark bands at the inside and outside surface of the cross section were approximately 0.003 " $(0.75 \mathrm{~mm})$ deep. This carburized layer was comprised predominantly of martensite with some indications of bainite. Carburizing can be performed at temperatures between $1550^{\circ} \mathrm{F}\left(840^{\circ} \mathrm{C}\right)$ and $1700^{\circ} \mathrm{F}\left(930^{\circ} \mathrm{C}\right)$. Because the carburized layer was relatively shallow on these parts, a lower temperature would be expected to have been used. At the lower temperature of the range, 1010 steel is in a two phase region (ferrite + austenite) on the iron-carbon phase diagram. Generally, the higher carbon content of the pearlitic areas of the as-manufactured tubing transform to austenite while the lower carbon areas of ferrite grains would be minimally affected. Again, using the phase diagram, a 1010 steel will not transform to $100 \%$ austenite until a temperature above $1600^{\circ} \mathrm{F}\left(870^{\circ} \mathrm{C}\right)$. This is further verification that the carburizing temperature was in the lower range. After carburizing the part is quenched to promote formation of martensite. Typically, a tempering treatment is performed to reduce the brittleness of the case.

Microhardness tests performed on the carburized case at the inside and outside surfaces indicated converted values of 36 and 41 on the Rockwell C scale. In the decarburized layer near the outside surface, hardness was converted to be 64 on the Rockwell B scale. Tests performed in the typical core area of the tube indicated values of 82 and 88 on the Rockwell B scale. Examples of the structures exhibited by this cross section are shown as photographs 1 and 2 . 


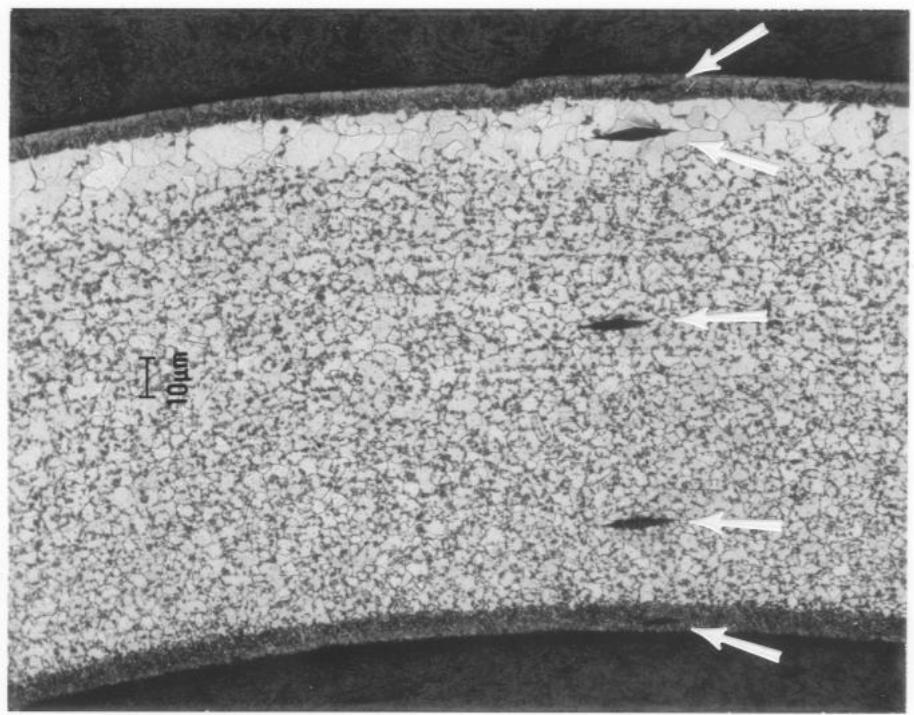

Photograph 1: An etched cross section of the elbow. Hardness impressions can be seen on the section in the carburized case, decarburized layer and in the core. Five hardness impressions (arrows) can be seen to the left of center. (mag: 40X)

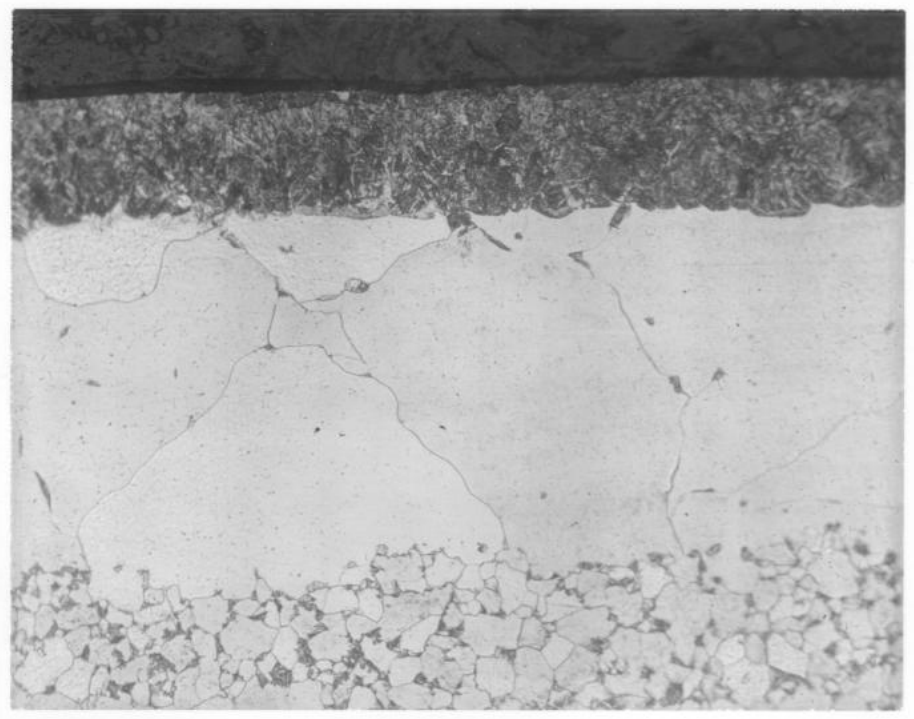

Photograph 2: The outside circumference of the tube displayed these microstructures. The dark carburized layer is at the surface. The light etching decarburized layer is below that and the core structure is shown near the bottom of the photograph. (mag: 160X) 